\title{
Hybrid methods for a mixed equilibrium problem and fixed points of a countable family of multivalued nonexpansive mappings
}

\section{Aunyarat Bunyawat and Suthep Suantai*}

"Correspondence:

suthep.s@cmu.ac.th Department of Mathematics, Faculty of Science, Chiang Mai University, Chiang Mai, 50200, Thailand

\begin{abstract}
In this paper, we prove a strong convergence theorem for a new hybrid method, using shrinking projection method introduced by Takahashi and a fixed point method for finding a common element of the set of solutions of mixed equilibrium problem and the set of common fixed points of a countable family of multivalued nonexpansive mappings in Hilbert spaces. We also apply our main result to the convex minimization problem and the fixed point problem of a countable family of multivalued nonexpansive mappings.
\end{abstract}

MSC: $47 \mathrm{H} 09 ; 47 \mathrm{H} 10$

Keywords: multivalued nonexpansive mappings; mixed equilibrium problem; shrinking projection method

\section{Introduction}

The mixed equilibrium problem (MEP) includes several important problems arising in optimization, economics, physics, engineering, transportation, network, Nash equilibrium problems in noncooperative games, and others. Variational inequalities and mathematical programming problems are also viewed as the abstract equilibrium problems (EP) (e.g., $[1,2])$. Many authors have proposed several methods to solve the EP and MEP, see, for instance, [1-9] and the references therein.

Fixed point problems for multivalued mappings are more difficult than those of singlevalued mappings and play very important role in applied science and economics. Recently, many authors have proposed their fixed point methods for finding a fixed point of both multivalued mapping and a family of multivalued mappings. All of those methods have only weak convergence.

It is known that Mann's iterations have only weak convergence even in the Hilbert spaces. To overcome this problem, Takahashi [10] introduced a new method, known as shrinking projection method, which is a hybrid method of Mann's iteration, and the projection method, and obtained strong convergence results of such method. In this paper, we use the shrinking projection method defined by Takahashi [10] and our new method to define a new hybrid method for MEP and a fixed point problem for a family of nonexpansive multivalued mappings.

C) 2013 Bunyawat and Suantai; licensee Springer. This is an Open Access article distributed under the terms of the Creative Commons Attribution License (http://creativecommons.org/licenses/by/2.0), which permits unrestricted use, distribution, and reproduction in any medium, provided the original work is properly cited. 
An element $p \in K$ is called a fixed point of a single-valued mapping $T$ if $p=T p$ and of a multivalued mapping $T$ if $p \in T p$. The set of fixed points of $T$ is denoted by $F(T)$.

Let $X$ be a real Banach space. A subset $K$ of $X$ is called proximinal if for each $x \in X$, there exists an element $k \in K$ such that

$$
d(x, k)=d(x, K)
$$

where $d(x, K)=\inf \{\|x-y\|: y \in K\}$ is the distance from the point $x$ to the set $K$.

Let $X$ be a uniformly convex real Banach space, and let $K$ be a nonempty closed convex subset of $X$, and let $C B(K)$ be a family of nonempty closed bounded subsets of $K$, and let $P(K)$ be a nonempty proximinal bounded subsets of $K$.

For multivalued mappings $T: K \rightarrow P(K)$, define $P_{T}(x):=\{y \in T(x):\|x-y\|=d(x, T(x))\}$ for all $x \in K$.

The Hausdorff metric on $C B(X)$ is defined by

$$
H(A, B)=\max \left\{\sup _{x \in A} d(x, B), \sup _{y \in B} d(y, A)\right\}
$$

for all $A, B \in C B(X)$.

A multivalued mapping $T: K \rightarrow C B(K)$ is said to be nonexpansive if $H(T x, T y) \leq\|x-y\|$ for all $x, y \in K$.

Let $H$ be a real Hilbert space with the inner product $\langle\cdot, \cdot\rangle$ and the norm $\|\cdot\|$. Let $D$ be a nonempty closed convex subset of $H$. Let $F: D \times D \rightarrow \mathbb{R}$ be a bifunction, and let $\varphi: D \rightarrow \mathbb{R} \cup\{+\infty\}$ be a function such that $D \cap \operatorname{dom} \varphi \neq \emptyset$, where $\mathbb{R}$ is the set of real numbers and $\operatorname{dom} \varphi=\{x \in H: \varphi(x)<+\infty\}$.

Flores-Bazán [11] introduced the following mixed equilibrium problem:

$$
\text { Find } x \in D \text { such that } F(x, y)+\varphi(y) \geq \varphi(x), \quad \forall y \in D \text {. }
$$

The set of solutions of (1.1) is denoted by $\operatorname{MEP}(F, \varphi)$.

If $\varphi \equiv 0$, then the mixed equilibrium problem (1.1) reduces to the following equilibrium problem:

$$
\text { Find } x \in D \text { such that } F(x, y) \geq 0, \quad \forall y \in D \text {. }
$$

The set of solutions of (1.2) is denoted by $E P(F)$ (see Combettes and Hirstoaga [12]).

If $F \equiv 0$, then the mixed equilibrium problem (1.1) reduces to the following convex minimization problem:

$$
\text { Find } x \in D \text { such that } \varphi(y) \geq \varphi(x), \quad \forall y \in D \text {. }
$$

The set of solutions of (1.3) is denoted by $\operatorname{CMP}(\varphi)$.

In an infinite-dimensional Hilbert space, the Mann iteration algorithms have only a weak convergence. In 2003, Nakajo and Takahashi [13] introduced the method, called CQ method, to modify Mann's iteration to obtain the strong convergence theorem for nonexpansive mapping in a Hilbert space. The CQ method has been studied extensively by many authors, for instance, Marino and Xu [14]; Zhou [15]; Zhang and Cheng [16]. 
In 2008, Takahashi et al. [10] introduced the following iteration scheme, which is usually called the shrinking projection method. Let $\left\{\alpha_{n}\right\}$ be a sequence in $(0,1)$ and $x_{0} \in H$. For $C_{1}=C$ and $x_{1}=P_{C_{1}} x_{0}$, define a sequence $\left\{x_{n}\right\}$ of $D$ as follows:

$$
\left\{\begin{array}{l}
y_{n}=\left(1-\alpha_{n}\right) x_{n}+\alpha_{n} T_{n} x_{n}, \\
C_{n+1}=\left\{z \in C_{n}:\left\|y_{n}-z\right\| \leq\left\|x_{n}-z\right\|\right\}, \\
x_{n+1}=P_{C_{n+1}} x_{0}, \quad n \geq 1,
\end{array}\right.
$$

where $P_{C_{n}}$ is the metric projection of $H$ onto $C_{n}$ and $\left\{T_{n}\right\}$ is a family of nonexpansive mappings. They proved that the sequence $\left\{x_{n}\right\}$ converges strongly to $z=P_{F(T)} x_{0}$, where $F(T)=\bigcap_{n=1}^{\infty} F\left(T_{n}\right)$. The shrinking projection method has been studied widely by many authors, for example, Tada and Takahashi [17]; Aoyama et al. [18]; Yao et al. [19]; Kang et al. [20]; Cholamjiak and Suantai [21]; Ceng et al. [22]; Tang et al. [23]; Cai and Bu [24]; Kumam et al. [25]; Kimura et al. [26]; Shehu [27, 28]; Wang et al. [29].

In 2009, Wangkeeree and Wangkeeree [30] proved a strong convergence theorem of an iterative algorithm based on extragradient method for finding a common element of the set of solutions of a mixed equilibrium problem, the set of common fixed points of a family of infinitely nonexpansive mappings and the set of the variational inequality for a monotone Lipschitz continuous mapping in a Hilbert space.

In 2011, Rodjanadid [31] introduced another iterative method modified from an iterative scheme of Klin-eam and Suantai [32] for finding a common element of the set of solutions of mixed equilibrium problems and the set of common fixed points of countable family of nonexpansive mappings in real Hilbert spaces. The mixed equilibrium problems have been studied by many authors, for instance, Peng and Yao [33]; Zeng et al. [34]; Peng et al. [35]; Wangkeeree and Kamraksa [36]; Jaiboon and Kumam [37]; Chamnarnpan and Kumam [38]; Cholamjiak et al. [39].

Nadler [40] started to study fixed points of multivalued contractions and nonexpansive mapping by using the Hausdorff metric.

Sastry and Babu [41] defined Mann and Ishikawa iterates for a multivalued map $T$ with a fixed point $p$, and proved that these iterates converge strongly to a fixed point $q$ of $T$ under the compact domain in a real Hilbert space. Moreover, they illustrated that fixed point $q$ may be different from $p$.

Panyanak [42] generalized results of Sastry and Babu [41] to uniformly convex Banach spaces and proved a strong convergence theorem of Mann iterates for a mapping defined on a noncompact domain and satisfying some conditions. He also obtained a strong convergence result of Ishikawa iterates for a mapping defined on a compact domain.

Hussain and Khan [43], in 2003, introduced the best approximation operator $P_{T}$ to find fixed points of *-nonexpansive multivalued mapping and proved strong convergence of its iterates on a closed convex unbounded subset of a Hilbert space, which is not necessarily compact.

Hu et al. [44] obtained common fixed point of two nonexpansive multivalued mappings satisfying certain contractive conditions.

Cholamjiak and Suantai [45] proved strong convergence theorems of two new iterative procedures with errors for two quasi-nonexpansive multivalued mappings by using the best approximation operator and the end point condition in uniformly convex Banach spaces. Later, Cholamjiak et al. [46] introduced a modified Mann iteration and obtained 
weak and strong convergence theorems for a countable family of nonexpansive multivalued mappings by using the best approximation operator in a Banach space. They also gave some examples of multivalued mappings $T$ such that $P_{T}$ are nonexpansive.

Later, Eslamian and Abkar [47] generalized and modified the iteration of Abbas et al. [48] from two mappings to the infinite family of multivalued mappings $\left\{T_{i}\right\}$ such that each $P_{T_{i}}$ satisfies the condition (C).

In this paper, we introduce a new hybrid method for finding a common element of the set of solutions of a mixed equilibrium problem and the set of common fixed points of a countable family of multivalued nonexpansive mappings in Hilbert spaces. We obtain a strong convergence theorem for the sequences generated by the proposed method without the assumption of compactness of the domain and other conditions imposing on the mappings.

In Section 2, we give some preliminaries and lemmas, which will be used in proving the main results. In Section 3, we introduce a new hybrid method and a fixed point method defined by (3.1) and prove strong convergence theorem for finding a common element of the set of solutions between mixed equilibrium problem and common fixed point problems of a countable family of multivalued nonexpansive mappings in Hilbert spaces. We also give examples of the control sequences satisfying the control conditions in main results. In Section 4, we summarize the main results of this paper.

\section{Preliminaries}

Let $D$ be a closed convex subset of $H$. For every point $x \in H$, there exists a unique nearest point in $D$, denoted by $P_{D} x$, such that

$$
\left\|x-P_{D} x\right\| \leq\|x-y\|, \quad \forall y \in D .
$$

$P_{D}$ is called the metric projection of $H$ onto $D$. It is known that $P_{D}$ is a nonexpansive mapping of $H$ onto $D$. It is also know that $P_{D}$ satisfies $\left\langle x-y, P_{D} x-P_{D} y\right\rangle \geq\left\|P_{D} x-P_{D} y\right\|^{2}$ for every $x, y \in H$. Moreover, $P_{D} x$ is characterized by the properties: $P_{D} x \in D$ and $\left\langle x-P_{D} x, P_{D} x-y\right\rangle \geq$ 0 for all $y \in D$.

Lemma 2.1 [13] Let D be a nonempty closed convex subset of a real Hilbert space $H$ and $P_{D}: H \rightarrow D$ be the metric projection from $H$ onto $D$. Then the following inequality holds:

$$
\left\|y-P_{D} x\right\|^{2}+\left\|x-P_{D} x\right\|^{2} \leq\|x-y\|^{2}, \quad \forall x \in H, \forall y \in D .
$$

Lemma 2.2 [14] Let $H$ be a real Hilbert space. Then the following equations hold:

(i) $\|x-y\|^{2}=\|x\|^{2}-\|y\|^{2}-2\langle x-y, y\rangle, \forall x, y \in H$;

(ii) $\|t x+(1-t) y\|^{2}=t\|x\|^{2}+(1-t)\|y\|^{2}-t(1-t)\|x-y\|^{2}, \forall t \in[0,1]$ and $x, y \in H$.

Lemma 2.3 [21] Let $H$ be a real Hilbert space. Then for each $m \in \mathbb{N}$

$$
\left\|\sum_{i=1}^{m} t_{i} x_{i}\right\|^{2}=\sum_{i=1}^{m} t_{i}\left\|x_{i}\right\|^{2}-\sum_{i=1, i \neq j}^{m} t_{i} t_{j}\left\|x_{i}-x_{j}\right\|^{2},
$$

$x_{i} \in H$ and $t_{i}, t_{j} \in[0,1]$ for all $i, j=1,2, \ldots, m$ with $\sum_{i=1}^{m} t_{i}=1$. 
Lemma 2.4 [49] Let D be a nonempty closed and convex subset of a real Hilbert space $H$. Given $x, y, z \in H$ and also given $a \in \mathbb{R}$, the set

$$
\left\{v \in D:\|y-v\|^{2} \leq\|x-v\|^{2}+\langle z, v\rangle+a\right\}
$$

is convex and closed.

For solving the mixed equilibrium problem, we assume the bifunction $F, \varphi$ and the set $D$ satisfy the following conditions:

(A1) $F(x, x)=0$ for all $x \in D$;

(A2) $F$ is monotone, that is, $F(x, y)+F(y, x) \leq 0$ for all $x, y \in D$;

(A3) for each $x, y, z \in D$, limsup $\operatorname{su}_{t \downarrow 0} F(t z+(1-t) x, y) \leq F(x, y)$;

(A4) $F(x, \cdot)$ is convex and lower semicontinuous for each $x \in D$;

(B1) for each $x \in H$ and $r>0$, there exist a bounded subset $D_{x} \subseteq D$ and $y_{x} \in D \cap \operatorname{dom} \varphi$ such that for any $z \in D \backslash D_{x}$,

$$
F\left(z, y_{x}\right)+\varphi\left(y_{x}\right)+\frac{1}{r}\left\langle y_{x}-z, z-x\right\rangle<\varphi(z)
$$

(B2) $D$ is a bounded set.

Lemma 2.5 [35] Let D be a nonempty closed and convex subset of a real Hilbert space $H$. Let $F: D \times D \rightarrow \mathbb{R}$ be a bifunction satisfying conditions (A1)-(A4) and $\varphi: D \rightarrow \mathbb{R} \cup\{+\infty\}$ be a proper lower semicontinuous and convex function such that $D \cap \operatorname{dom} \varphi \neq \emptyset$. For $r>0$ and $x \in D$, define a mapping $T_{r}: H \rightarrow D$ as follows:

$$
T_{r}(x)=\left\{z \in D: F(z, y)+\varphi(y)+\frac{1}{r}\langle y-z, z-x\rangle \geq \varphi(z), \forall y \in D\right\}
$$

for all $x \in H$. Assume that either (B1) or (B2) holds. Then the following conclusions hold:

(1) for each $x \in H, T_{r}(x) \neq \emptyset$;

(2) $T_{r}$ is single-valued;

(3) $T_{r}$ is firmly nonexpansive, that is, for any $x, y \in H$,

$$
\left\|T_{r}(x)-T_{r}(y)\right\|^{2} \leq\left\langle T_{r}(x)-T_{r}(y), x-y\right|
$$

(4) $F\left(T_{r}\right)=\operatorname{MEP}(F, \varphi)$;

(5) $\operatorname{MEP}(F, \varphi)$ is closed and convex.

As in ([21], Lemma 2.7), the following lemma holds true for multivalued mapping. To avoid repetition, we omit the details of proof.

Lemma 2.6 Let D be a closed and convex subset of a real Hilbert space H. Let $T: D \rightarrow P(D)$ be a multivalued nonexpansive mapping with $F(T) \neq \emptyset$ such that $P_{T}$ is nonexpansive. Then $F(T)$ is a closed and convex subset of $D$. 


\section{Main results}

In the following theorem, we prove strong convergence of the sequence $\left\{x_{n}\right\}$ defined by (3.1) to a common element of the set of solutions of a mixed equilibrium problem and the set of common fixed points of a countable family of multivalued nonexpansive mappings.

Theorem 3.1 Let $D$ be a nonempty closed and convex subset of a real Hilbert space $H$. Let $F$ be a bifunction from $D \times D$ to $\mathbb{R}$ satisfying (A1)-(A4), and let $\varphi$ be a proper lower semicontinuous and convex function from $D$ to $\mathbb{R} \cup\{+\infty\}$ such that $D \cap \operatorname{dom} \varphi \neq \emptyset$. Let $T_{i}: D \rightarrow P(D)$ be multivalued nonexpansive mappings for all $i \in \mathbb{N}$ with $\Omega:=\bigcap_{i=1}^{\infty} F\left(T_{i}\right) \cap$ $\operatorname{MEP}(F, \varphi) \neq \emptyset$ such that all $P_{T_{i}}$ are nonexpansive. Assume that either (B1) or (B2) holds and $\left\{\alpha_{n, i}\right\} \subset[0,1)$ satisfies the condition $\liminf _{n \rightarrow \infty} \alpha_{n, i} \alpha_{n, 0}>0$ for all $i \in \mathbb{N}$. Define the sequence $\left\{x_{n}\right\}$ as follows: $x_{1} \in D=C_{1}$,

$$
\left\{\begin{array}{l}
F\left(u_{n}, y\right)+\varphi(y)-\varphi\left(u_{n}\right)+\frac{1}{r_{n}}\left\langle y-u_{n}, u_{n}-x_{n}\right\rangle \geq 0, \quad \forall y \in D \\
y_{n}=\alpha_{n, 0} u_{n}+\sum_{i=1}^{n} \alpha_{n, i} x_{n, i} \\
C_{n+1}=\left\{z \in C_{n}:\left\|y_{n}-z\right\| \leq\left\|x_{n}-z\right\|\right\} \\
x_{n+1}=P_{C_{n+1}} x_{0}, \quad n \geq 0
\end{array}\right.
$$

where the sequences $r_{n} \in(0, \infty)$ with $\liminf _{n \rightarrow \infty} r_{n}>0$ and $\left\{\alpha_{n, i}\right\} \subset[0,1)$ satisfying $\sum_{i=0}^{n} \alpha_{n, i}=1$ and $x_{n, i} \in P_{T_{i}} u_{n}$ for $i \in \mathbb{N}$. Then the sequence $\left\{x_{n}\right\}$ converges strongly to $P_{\Omega} x_{0}$.

Proof We split the proof into six steps.

Step 1. Show that $P_{C_{n+1}} x_{0}$ is well defined for every $x_{0} \in D$.

By Lemmas 2.5-2.6, we obtain that $\operatorname{MEP}(F, \varphi)$ and $\bigcap_{i=1}^{\infty} F\left(T_{i}\right)$ is a closed and convex subset of $D$. Hence $\Omega$ is a closed and convex subset of $D$. It follows from Lemma 2.4 that $C_{n+1}$ is a closed and convex for each $n \geq 0$. Let $v \in \Omega$. Then $P_{T_{i}}(v)=\{v\}$ for all $i \in \mathbb{N}$. Since $u_{n}=T_{r_{n}} x_{n} \in \operatorname{dom} \varphi$, we have

$$
\left\|u_{n}-v\right\|=\left\|T_{r_{n}} x_{n}-T_{r_{n}} v\right\| \leq\left\|x_{n}-v\right\|,
$$

for every $n \geq 0$. Then

$$
\begin{aligned}
\left\|y_{n}-v\right\| & =\left\|\alpha_{n, 0} u_{n}+\sum_{i=1}^{n} \alpha_{n, i} x_{n, i}-v\right\| \\
& \leq \alpha_{n, 0}\left\|u_{n}-v\right\|+\sum_{i=1}^{n} \alpha_{n, i}\left\|x_{n, i}-v\right\| \\
& =\alpha_{n, 0}\left\|u_{n}-v\right\|+\sum_{i=1}^{n} \alpha_{n, i} d\left(x_{n, i}, P_{T_{i}} v\right) \\
& \leq \alpha_{n, 0}\left\|u_{n}-v\right\|+\sum_{i=1}^{n} \alpha_{n, i} H\left(P_{T_{i}} u_{n}, P_{T_{i}} v\right) \\
& \leq \alpha_{n, 0}\left\|u_{n}-v\right\|+\sum_{i=1}^{n} \alpha_{n, i}\left\|u_{n}-v\right\| \\
& =\left\|u_{n}-v\right\| \leq\left\|x_{n}-v\right\| .
\end{aligned}
$$

Hence $v \in C_{n+1}$, so that $\Omega \subset C_{n+1}$. Therefore, $P_{C_{n+1}} x_{0}$ is well defined. 
Step 2. Show that $\lim _{n \rightarrow \infty}\left\|x_{n}-x_{0}\right\|$ exists.

Since $\Omega$ is a nonempty closed convex subset of $H$, there exists a unique $v \in \Omega$ such that $v=P_{\Omega} x_{0}$. Since $x_{n}=P_{C_{n}} x_{0}$ and $x_{n+1} \in C_{n+1} \subset C_{n}, \forall n \geq 0$, we have

$$
\left\|x_{n}-x_{0}\right\| \leq\left\|x_{n+1}-x_{0}\right\|, \quad \forall n \geq 0 .
$$

On the other hand, as $v \in \Omega \subset C_{n}$, we obtain

$$
\left\|x_{n}-x_{0}\right\| \leq\left\|v-x_{0}\right\|, \quad \forall n \geq 0 .
$$

It follows that the sequence $\left\{x_{n}\right\}$ is bounded and nondecreasing. Therefore, $\lim _{n \rightarrow \infty} \| x_{n}-$ $x_{0} \|$ exists.

Step 3. Show that $\lim _{n \rightarrow \infty} x_{n}=w \in D$.

For $m>n$, by the definition of $C_{n}$, we get $x_{m}=P_{C_{m}} x_{0} \in C_{m} \subset C_{n}$. By applying Lemma 2.1, we have

$$
\left\|x_{m}-x_{n}\right\|^{2} \leq\left\|x_{m}-x_{0}\right\|^{2}-\left\|x_{n}-x_{0}\right\|^{2} .
$$

Since $\lim _{n \rightarrow \infty}\left\|x_{n}-x_{0}\right\|$ exists, it follows that $\left\{x_{n}\right\}$ is Cauchy. Hence there exists $w \in D$ such that $\lim _{n \rightarrow \infty} x_{n}=w$.

Step 4 . Show that $\left\|x_{n, i}-x_{n}\right\| \rightarrow 0$ as $n \rightarrow \infty$ for every $i \in \mathbb{N}$.

From $x_{n+1} \in C_{n+1}$, we have

$$
\begin{aligned}
\left\|x_{n}-y_{n}\right\| & \leq\left\|x_{n}-x_{n+1}\right\|+\left\|x_{n+1}-y_{n}\right\| \\
& \leq 2\left\|x_{n}-x_{n+1}\right\| \rightarrow 0 \quad \text { as } n \rightarrow \infty
\end{aligned}
$$

For $v \in \Omega$, by Lemma 2.3 and (3.2), we get

$$
\begin{aligned}
\left\|y_{n}-v\right\|^{2} & =\left\|\alpha_{n, 0}\left(u_{n}-v\right)+\sum_{i=1}^{n} \alpha_{n, i}\left(x_{n, i}-v\right)\right\|^{2} \\
& \leq \alpha_{n, 0}\left\|u_{n}-v\right\|^{2}+\sum_{i=1}^{n} \alpha_{n, i}\left\|x_{n, i}-v\right\|^{2}-\sum_{i=1}^{n} \alpha_{n, i} \alpha_{n, 0}\left\|x_{n, i}-u_{n}\right\|^{2} \\
& =\alpha_{n, 0}\left\|u_{n}-v\right\|^{2}+\sum_{i=1}^{n} \alpha_{n, i} d\left(x_{n, i}, P_{T_{i}} v\right)^{2}-\sum_{i=1}^{n} \alpha_{n, i} \alpha_{n, 0}\left\|x_{n, i}-u_{n}\right\|^{2} \\
& \leq \alpha_{n, 0}\left\|u_{n}-v\right\|^{2}+\sum_{i=1}^{n} \alpha_{n, i} H\left(P_{T_{i}} u_{n}, P_{T_{i}} v\right)^{2}-\sum_{i=1}^{n} \alpha_{n, i} \alpha_{n, 0}\left\|x_{n, i}-u_{n}\right\|^{2} \\
& \leq \alpha_{n, 0}\left\|u_{n}-v\right\|^{2}+\sum_{i=1}^{n} \alpha_{n, i}\left\|u_{n}-v\right\|^{2}-\sum_{i=1}^{n} \alpha_{n, i} \alpha_{n, 0}\left\|x_{n, i}-u_{n}\right\|^{2} \\
& =\left\|u_{n}-v\right\|^{2}-\sum_{i=1}^{n} \alpha_{n, i} \alpha_{n, 0}\left\|x_{n, i}-u_{n}\right\|^{2} \\
& \leq\left\|x_{n}-v\right\|^{2}-\sum_{i=1}^{n} \alpha_{n, i} \alpha_{n, 0}\left\|x_{n, i}-u_{n}\right\|^{2} .
\end{aligned}
$$


This implies that

$$
\begin{aligned}
\alpha_{n, i} \alpha_{n, 0}\left\|x_{n, i}-u_{n}\right\|^{2} & \leq \sum_{i=1}^{n} \alpha_{n, i} \alpha_{n, 0}\left\|x_{n, i}-u_{n}\right\|^{2} \\
& \leq\left\|x_{n}-v\right\|^{2}-\left\|y_{n}-v\right\|^{2} \\
& \leq M\left\|x_{n}-y_{n}\right\|,
\end{aligned}
$$

where $M=\sup _{n \geq 0}\left\{\left\|x_{n}-v\right\|+\left\|y_{n}-v\right\|\right\}$. By the given control condition on $\left\{\alpha_{n, i}\right\}$ and (3.3), we obtain

$$
\lim _{n \rightarrow \infty}\left\|x_{n, i}-u_{n}\right\|=0, \quad \forall i \in \mathbb{N} .
$$

By Lemma 2.5, we have

$$
\begin{aligned}
\left\|u_{n}-v\right\|^{2} & =\left\|T_{r_{n}} x_{n}-T_{r_{n}} v\right\|^{2} \\
& \leq\left\langle T_{r_{n}} x_{n}-T_{r_{n}} v, x_{n}-v\right\rangle \\
& =\left\langle u_{n}-v, x_{n}-v\right\rangle \\
& =\frac{1}{2}\left\{\left\|u_{n}-v\right\|^{2}+\left\|x_{n}-v\right\|^{2}-\left\|x_{n}-u_{n}\right\|^{2}\right\} .
\end{aligned}
$$

Hence $\left\|u_{n}-v\right\|^{2} \leq\left\|x_{n}-v\right\|^{2}-\left\|x_{n}-u_{n}\right\|^{2}$. By Lemma 2.3, we get

$$
\begin{aligned}
\left\|y_{n}-v\right\|^{2} & =\left\|\alpha_{n, 0} u_{n}+\sum_{i=1}^{n} \alpha_{n, i} x_{n, i}-v\right\|^{2} \\
& =\alpha_{n, 0}\left\|u_{n}-v\right\|^{2}+\sum_{i=1}^{n} \alpha_{n, i}\left\|x_{n, i}-v\right\|^{2}-\sum_{i=1}^{n} \alpha_{n, i} \alpha_{n, 0}\left\|x_{n, i}-u_{n}\right\|^{2} \\
& \leq \alpha_{n, 0}\left\|u_{n}-v\right\|^{2}+\sum_{i=1}^{n} \alpha_{n, i}\left\|x_{n, i}-v\right\|^{2} \\
& =\alpha_{n, 0}\left\|u_{n}-v\right\|^{2}+\sum_{i=1}^{n} \alpha_{n, i} d\left(x_{n, i}, P_{T_{i}} v\right)^{2} \\
& \leq \alpha_{n, 0}\left\|u_{n}-v\right\|^{2}+\sum_{i=1}^{n} \alpha_{n, i} H\left(P_{T_{i}} u_{n}, P_{T_{i}} v\right)^{2} \\
& \leq \alpha_{n, 0}\left\|u_{n}-v\right\|^{2}+\sum_{i=1}^{n} \alpha_{n, i}\left\|u_{n}-v\right\|^{2} \\
& =\left\|u_{n}-v\right\|^{2} \\
& \leq\left\|x_{n}-v\right\|^{2}-\left\|x_{n}-u_{n}\right\|^{2} .
\end{aligned}
$$

This implies that

$$
\begin{aligned}
\left\|x_{n}-u_{n}\right\|^{2} & \leq\left\|x_{n}-v\right\|^{2}-\left\|y_{n}-v\right\|^{2} \\
& \leq M\left\|x_{n}-y_{n}\right\|
\end{aligned}
$$


where $M=\sup _{n \geq 0}\left\{\left\|x_{n}-v\right\|+\left\|y_{n}-v\right\|\right\}$. From (3.3), we get $\lim _{n \rightarrow \infty}\left\|x_{n}-u_{n}\right\|=0$. It follows that

$$
\begin{aligned}
\left\|x_{n, i}-x_{n}\right\| & \leq\left\|x_{n, i}-u_{n}\right\|+\left\|u_{n}-x_{n}\right\| \\
& \rightarrow 0 \quad \text { as } n \rightarrow \infty .
\end{aligned}
$$

Step 5. Show that $w \in \Omega$.

By $\liminf _{n \rightarrow \infty} r_{n}>0$, we have

$$
\left\|\frac{x_{n}-u_{n}}{r_{n}}\right\|=\frac{1}{r_{n}}\left\|x_{n}-u_{n}\right\| \rightarrow 0, \quad n \rightarrow \infty .
$$

From $\lim _{n \rightarrow \infty} x_{n}=w$, we obtain $\lim _{n \rightarrow \infty} u_{n}=w$.

We will show that $w \in \operatorname{MEP}(F, \varphi)$. Since $u_{n}=T_{r_{n}} x_{n} \in \operatorname{dom} \varphi$, we have

$$
F\left(u_{n}, y\right)+\varphi(y)-\varphi\left(u_{n}\right)+\frac{1}{r_{n}}\left\langle y-u_{n}, u_{n}-x_{n}\right\rangle \geq 0, \quad \forall y \in D
$$

It follows by (A2) that

$$
\varphi(y)-\varphi\left(u_{n}\right)+\frac{1}{r_{n}}\left\langle y-u_{n}, u_{n}-x_{n}\right\rangle \geq F\left(y, u_{n}\right), \quad \forall y \in D .
$$

Hence

$$
\varphi(y)-\varphi\left(u_{n}\right)+\left\langle y-u_{n}, \frac{u_{n}-x_{n}}{r_{n}}\right\rangle \geq F\left(y, u_{n}\right), \quad \forall y \in D
$$

It follows from (3.4), (A4) and the lower semicontinuous of $\varphi$ that

$$
F(y, w)+\varphi(w)-\varphi(y) \leq 0, \quad \forall y \in D .
$$

For $t$ with $0<t \leq 1$ and $y \in D$, let $y_{t}=t y+(1-t) w$. Since $y, w \in D$ and $D$ is convex, then $y_{t} \in D$ and hence

$$
F\left(y_{t}, w\right)+\varphi(w)-\varphi\left(y_{t}\right) \leq 0
$$

This implies by (A1), (A4) and the convexity of $\varphi$, that

$$
\begin{aligned}
0 & =F\left(y_{t}, y_{t}\right)+\varphi\left(y_{t}\right)-\varphi\left(y_{t}\right) \\
& \leq t F\left(y_{t}, y\right)+(1-t) F\left(y_{t}, w\right)+t \varphi(y)+(1-t) \varphi(w)-\varphi\left(y_{t}\right) \\
& \leq t\left[F\left(y_{t}, y\right)+\varphi(y)-\varphi\left(y_{t}\right)\right] .
\end{aligned}
$$

Dividing by $t$, we have

$$
F\left(y_{t}, y\right)+\varphi(y)-\varphi\left(y_{t}\right) \geq 0, \quad \forall y \in D
$$


Letting $t \rightarrow 0$, it follows from the weakly semicontinuity of $\varphi$ that

$$
F(w, y)+\varphi(y)-\varphi(w) \geq 0, \quad \forall y \in D
$$

Hence $w \in \operatorname{MEP}(F, \varphi)$. Next, we will show that $w \in \bigcap_{i=1}^{\infty} F\left(T_{i}\right)$. For each $i=1,2, \ldots, n$, we have

$$
\begin{aligned}
d\left(w, T_{i} w\right) & \leq d\left(w, x_{n}\right)+d\left(x_{n}, x_{n, i}\right)+d\left(x_{n, i}, T_{i} w\right) \\
& \leq d\left(w, x_{n}\right)+d\left(x_{n}, x_{n, i}\right)+H\left(T_{i} u_{n}, T_{i} w\right) \\
& \leq d\left(w, x_{n}\right)+d\left(x_{n}, x_{n, i}\right)+d\left(u_{n}, w\right)
\end{aligned}
$$

By Steps 3-4, we have $d\left(w, T_{i} w\right)=0$. Hence $w \in T_{i} w$ for all $i=1,2, \ldots, n$.

Step 6. Show that $w=P_{\Omega} x_{0}$.

Since $x_{n}=P_{C_{n}} x_{0}$, we get

$$
\left\langle z-x_{n}, x_{0}-x_{n}\right\rangle \leq 0, \quad \forall z \in C_{n} .
$$

Since $w \in \Omega \subset C_{n}$, we have

$$
\left\langle z-w, x_{0}-w\right\rangle \leq 0, \quad \forall z \in \Omega
$$

Now, we obtain that $w=P_{\Omega} x_{0}$.

This completes the proof.

Setting $\varphi \equiv 0$ in Theorem 3.1, we have the following result.

Corollary 3.2 Let D be a nonempty closed and convex subset of a real Hilbert space H. Let $F$ be a bifunction from $D \times D$ to $\mathbb{R}$ satisfying (A1)-(A4). Let $T_{i}: D \rightarrow P(D)$ be multivalued nonexpansive mappings for all $i \in \mathbb{N}$ with $\Omega:=\bigcap_{i=1}^{\infty} F\left(T_{i}\right) \cap E P(F) \neq \emptyset$ such that all $P_{T_{i}}$ are nonexpansive. Assume that $\left\{\alpha_{n, i}\right\} \subset[0,1)$ satisfies the condition $\liminf _{n \rightarrow \infty} \alpha_{n, i} \alpha_{n, 0}>0$ for all $i \in \mathbb{N}$. Define the sequence $\left\{x_{n}\right\}$ as follows: $x_{1} \in D=C_{1}$,

$$
\left\{\begin{array}{l}
F\left(u_{n}, y\right)+\frac{1}{r_{n}}\left\langle y-u_{n}, u_{n}-x_{n}\right\rangle \geq 0, \quad \forall y \in D, \\
y_{n}=\alpha_{n, 0} u_{n}+\sum_{i=1}^{n} \alpha_{n, i} x_{n, i}, \\
C_{n+1}=\left\{z \in C_{n}:\left\|y_{n}-z\right\| \leq\left\|x_{n}-z\right\|\right\}, \\
x_{n+1}=P_{C_{n+1}} x_{0}, \quad n \geq 0,
\end{array}\right.
$$

where the sequences $r_{n} \in(0, \infty)$ with $\liminf _{n \rightarrow \infty} r_{n}>0$ and $\left\{\alpha_{n, i}\right\} \subset[0,1)$ satisfying $\sum_{i=0}^{n} \alpha_{n, i}=1$ and $x_{n, i} \in P_{T_{i}} u_{n}$ for $i \in \mathbb{N}$. Then the sequence $\left\{x_{n}\right\}$ converges strongly to $P_{\Omega} x_{0}$.

Setting $F \equiv 0$ in Theorem 3.1, we have the following result.

Corollary 3.3 Let D be a nonempty closed and convex subset of a real Hilbert space H. Let $\varphi$ be a proper lower semicontinuous and convex function from $D$ to $\mathbb{R} \cup\{+\infty\}$ such that $D \cap \operatorname{dom} \varphi \neq \emptyset$. Let $T_{i}: D \rightarrow P(D)$ be multivalued nonexpansive mappings for all $i \in \mathbb{N}$ with $\Omega:=\bigcap_{i=1}^{\infty} F\left(T_{i}\right) \cap C M P(\varphi) \neq \emptyset$ such that all $P_{T_{i}}$ are nonexpansive. Assume that either (B1) or (B2) holds, and $\left\{\alpha_{n, i}\right\} \subset[0,1)$ satisfies the condition $\liminf _{n \rightarrow \infty} \alpha_{n, i} \alpha_{n, 0}>0$ for all $i \in \mathbb{N}$. 
Define the sequence $\left\{x_{n}\right\}$ as follows: $x_{1} \in D=C_{1}$,

$$
\left\{\begin{array}{l}
\varphi(y)-\varphi\left(u_{n}\right)+\frac{1}{r_{n}}\left\langle y-u_{n}, u_{n}-x_{n}\right\rangle \geq 0, \quad \forall y \in D \\
y_{n}=\alpha_{n, 0} u_{n}+\sum_{i=1}^{n} \alpha_{n, i} x_{n, i}, \\
C_{n+1}=\left\{z \in C_{n}:\left\|y_{n}-z\right\| \leq\left\|x_{n}-z\right\|\right\}, \\
x_{n+1}=P_{C_{n+1}} x_{0}, \quad n \geq 0
\end{array}\right.
$$

where the sequences $r_{n} \in(0, \infty)$ with $\liminf _{n \rightarrow \infty} r_{n}>0$ and $\left\{\alpha_{n, i}\right\} \subset[0,1)$ satisfying $\sum_{i=0}^{n} \alpha_{n, i}=1$ and $x_{n, i} \in P_{T_{i}} u_{n}$ for $i \in \mathbb{N}$. Then the sequence $\left\{x_{n}\right\}$ converges strongly to $P_{\Omega} x_{0}$.

\section{Remark 3.4}

(i) Let $\left\{\alpha_{n, i}\right\}$ be double sequence in $(0,1]$. Let (a) and (b) be the following conditions:

(a) $\liminf _{n \rightarrow \infty} \alpha_{n, i} \alpha_{n, 0}>0$ for all $i \in \mathbb{N}$,

(b) $\lim _{n \rightarrow \infty} \alpha_{n, i}$ exist and lie in $(0,1]$ for all $i=0,1,2, \ldots$.

It is easy to see that if $\left\{\alpha_{n, i}\right\}$ satisfies the condition (a), then it satisfies the condition (b). So Theorem 3.1 and Corollaries 3.2-3.3 hold true when the control double sequence $\left\{\alpha_{n, i}\right\}$ satisfies the condition (a).

(ii) The following double sequences are examples of the control sequences in Theorem 3.1 and Corollaries 3.2-3.3:

(1)

$$
\alpha_{n, k}= \begin{cases}\frac{1}{2^{k}}\left(\frac{n}{n+1}\right), & n \geq k \\ 1-\frac{n}{n+1}\left(\sum_{k=1}^{n} \frac{1}{2^{k}}\right), & n=k-1 \\ 0, & n<k-1\end{cases}
$$

that is,

$$
\alpha_{n, k}=\left(\begin{array}{ccccccccc}
\frac{1}{4} & \frac{3}{4} & 0 & 0 & 0 & 0 & \cdots & 0 & \cdots \\
\frac{1}{3} & \frac{1}{6} & \frac{1}{2} & 0 & 0 & 0 & \cdots & 0 & \cdots \\
\frac{3}{8} & \frac{3}{16} & \frac{3}{32} & \frac{11}{32} & 0 & 0 & \cdots & 0 & \cdots \\
\frac{2}{5} & \frac{1}{5} & \frac{1}{10} & \frac{1}{20} & \frac{1}{4} & 0 & \cdots & 0 & \cdots \\
\vdots & \vdots & \vdots & \vdots & \vdots & \vdots & & \vdots & \\
\frac{n}{2(n+1)} & \frac{n}{4(n+1)} & \frac{n}{8(n+1)} & \frac{n}{16(n+1)} & \frac{n}{32(n+1)} & \frac{n}{64(n+1)} & \cdots & \frac{n}{2^{k}(n+1)} & \cdots \\
\vdots & \vdots & \vdots & \vdots & \vdots & \vdots & & \vdots &
\end{array}\right) .
$$

We see that $\lim _{n \rightarrow \infty} \alpha_{n, k}=\frac{1}{2^{k}}$ and $\liminf _{n \rightarrow \infty} \alpha_{n, 0} \alpha_{n, k}=\frac{1}{2^{k+1}}$ for $k=1,2,3, \ldots$

(2)

$$
\alpha_{n, k}= \begin{cases}\frac{1}{2^{k}}\left(\frac{n}{n+1}\right), & n \geq k \text { and } n \text { is odd; } \\ \frac{1}{2^{k+1}}\left(\frac{n}{n+1}\right), & n \geq k \text { and } n \text { is even; } \\ 1-\frac{n}{n+1}\left(\sum_{k=1}^{n} \frac{1}{2^{k}}\right), & n=k-1 \text { and } n \text { is odd; } \\ 1-\frac{n}{n+1}\left(\sum_{k=1}^{n} \frac{1}{2^{k+1}}\right), & n=k-1 \text { and } n \text { is even; } \\ 0, & n<k-1,\end{cases}
$$


that is,

$$
\alpha_{n, k}=\left(\begin{array}{ccccccccc}
\frac{1}{4} & \frac{3}{4} & 0 & 0 & 0 & 0 & \ldots & 0 & \ldots \\
\frac{1}{6} & \frac{1}{12} & \frac{3}{4} & 0 & 0 & 0 & \ldots & 0 & \ldots \\
\frac{3}{8} & \frac{3}{16} & \frac{3}{32} & \frac{11}{32} & 0 & 0 & \ldots & 0 & \ldots \\
\frac{1}{5} & \frac{1}{10} & \frac{1}{20} & \frac{1}{40} & \frac{5}{8} & 0 & \ldots & 0 & \ldots \\
\vdots & \vdots & \vdots & \vdots & \vdots & \vdots & & \vdots & \\
\frac{2 n-1}{2(2 n)} & \frac{2 n-1}{4(2 n)} & \frac{2 n-1}{8(2 n)} & \frac{2 n-1}{16(2 n)} & \frac{2 n-1}{32(2 n)} & \frac{2 n-1}{64(2 n)} & \ldots & \frac{2 n-1}{2^{k}(2 n)} & \ldots \\
\frac{2 n}{4(2 n+1)} & \frac{2 n}{8(2 n+1)} & \frac{2 n}{16(2 n+1)} & \frac{2 n}{32(2 n+1)} & \frac{2 n}{64(2 n+1)} & \frac{2 n}{128(2 n+1)} & \cdots & \frac{2 n}{2^{k+1}(2 n+1)} & \ldots \\
\vdots & \vdots & \vdots & \vdots & \vdots & \vdots & & \vdots &
\end{array}\right) .
$$

We see that $\lim _{n \rightarrow \infty} \alpha_{n, k}$ does not exist and $\liminf _{n \rightarrow \infty} \alpha_{n, 0} \alpha_{n, k}=\frac{1}{2^{k+3}}$ for $k=1,2,3, \ldots$.

\section{Conclusions}

We use the shrinking projection method defined by Takahashi [10] together with our method for finding a common element of the set of solutions of mixed equilibrium problem and common fixed points of a countable family of multivalued nonexpansive mappings in Hilbert spaces. The main results of paper can be applied for solving convex minimization problems and fixed point problems.

\section{Competing interests}

The authors declare that they have no competing interests.

\section{Authors' contributions}

AB studied and researched a nonlinear analysis and also wrote this article. SS participated in the process of the study and helped to draft the manuscript. All authors read and approved the final manuscript.

\section{Acknowledgements}

The authors would like to thank Chiang Mai University, Chiang Mai, Thailand for the financial support of this paper.

Received: 7 May 2013 Accepted: 6 August 2013 Published: 16 September 2013

\section{References}

1. Blum, E, Oettli, W: From optimization and variational inequalities to equilibrium problems. Math. Stud. 63(14), 123-145 (1994)

2. Noor, MA, Oettli, W: On general nonlinear complementarity problems and quasi-equilibria. Matematiche $49(2)$, 313-331 (1994)

3. Moudafi, A, Thera, M: Proximal and dynamical approaches to equilibrium problems. In: III-Posed Variational Problems and Regularization Techniques (Trier, 1998). Lecture Notes in Economics and Mathematical Systems, vol. 477, pp. 187-201. Springer, Berlin (1999)

4. Peng, JW, Yao, JC: Two extragradient methods for generalized mixed equilibrium problems, nonexpansive mappings and monotone mappings. Comput. Math. Appl. 58(7), 1287-1301 (2009)

5. Jaiboon, C, Kumam, P: A hybrid extragradient viscosity approximation method for solving equilibrium problems and fixed point problems of infinitely many nonexpansive mappings. Fixed Point Theory Appl. 2009, Article ID 374815 (2009)

6. Liu, QY, Zeng, WY, Huang, NJ: An iterative method for generalized equilibrium problems, fixed point problems and variational inequality problems. Fixed Point Theory Appl. 2009, Article ID 531308 (2009)

7. Peng, JW, Yao, J: A viscosity approximation scheme for system of equilibrium problems, nonexpansive mappings and monotone mappings. Nonlinear Anal. 71(12), 6001-6010 (2009)

8. Kumam, $\mathrm{P}$, Jaiboon, C: A new hybrid iterative method for mixed equilibrium problems and variational inequality problem for relaxed cocoercive mappings with application to optimization problems. Nonlinear Anal. Hybrid Syst. 3(4), 510-530 (2009)

9. Chang, SS, Chan, CK, Lee, HWJ, Yang, L: A system of mixed equilibrium problems, fixed point problems of strictly pseudo-contractive mappings and nonexpansive semi-groups. Appl. Math. Comput. 216(1), 51-60 (2010)

10. Takahashi, W, Takeuchi, Y, Kubota, R: Strong convergence theorems by hybrid methods for families of nonexpansive mappings in Hilbert spaces. J. Math. Anal. Appl. 341, 276-286 (2008)

11. Flores-Bazán, F: Existence theorems for generalized noncoercive equilibrium problems: the quasi-convex case. SIAM J. Control Optim. 11(3), 675-690 (2000) 
12. Combettes, PL, Hirstoaga, SA: Equilibrium programming in Hilbert spaces. J. Nonlinear Convex Anal. 6(1), 117-136 (2005)

13. Nakajo, K, Takahashi, W: Strongly convergence theorems for nonexpansive mappings and nonexpansive semigroups J. Math. Anal. Appl. 279, 372-379 (2003)

14. Marino, G, Xu, HK: Weak and strong convergence theorems for strict pseudo-contractions in Hilbert spaces. J. Math. Anal. Appl. 329, 336-346 (2007)

15. Zhou, HY: Convergence theorems of fixed points for Lipschitz pseudo-contractions in Hilbert spaces. J. Math. Anal. Appl. 343, 546-556 (2008)

16. Zhang, QB, Cheng, CZ: Strong convergence theorem for a family of Lipschitz pseudocontractive mappings in a Hilbert space. Math. Comput. Model. 48, 480-485 (2008)

17. Tada, A, Takahashi, W: Weak and strong convergence theorems for a nonexpansive mapping and equilibrium problem. J. Optim. Theory Appl. 133, 359-370 (2007)

18. Aoyama, K, Kohsaka, F, Takahashi, W: Shrinking projection methods for firmly nonexpansive mappings. Nonlinear Anal. 71, 1626-1632 (2009)

19. Yao, YH, Liou, YC, Marino, G: A hybrid algorithm for pseudo-contractive mappings. Nonlinear Anal. 71, 4997-5002 (2009)

20. Kang, JL, Su, YF, Zhang, X: Shrinking projection algorithm for fixed points of firmly nonexpansive mappings and its applications. Fixed Point Theory 11(2), 301-310 (2010)

21. Cholamjiak, W, Suantai, S: A hybrid method for a countable family of multivalued maps, equilibrium problems, and variational inequality problems. Discrete Dyn. Nat. Soc. 2010, Article ID 349158 (2010). doi:10.1155/2010/349158

22. Ceng, LC, Ansari, QH, Yao, JC: Hybrid proximal-type and hybrid shrinking projection algorithms for equilibrium problems, maximal monotone operators, and relatively nonexpansive mappings. Numer. Funct. Anal. Optim. 31(7), 763-797 (2010). doi:10.1080/01630563.2010.496697

23. Tang, YC, Peng, JG, Liu, LW: Strong convergence theorem for pseudo-contractive mappings in Hilbert spaces. Nonlinear Anal. 74, 380-385 (2011)

24. Cai, G, Bu, S: Hybrid algorithm for generalized mixed equilibrium problems and variational inequality problems and fixed point problems. Comput. Math. Appl. 62, 4772-4782 (2011)

25. Kumam, P, Hamphries, U, Katchang, P: Common solutions of generalized mixed equilibrium problems, variational inclusions, and common fixed points for nonexpansive semigroups and strictly pseudocontractive mappings. J. Appl. Math. 2011, Article ID 953903 (2011). doi:10.1155/2011/953903

26. Kimura, Y, Takahashi, W, Yao, JC: Strong convergence of an iterative scheme by a new type of projection method for a family of quasinonexpansive mappings. J. Optim. Theory Appl. 149, 239-253 (2011). doi:10.1007/s10957-010-9788-9

27. Shehu, Y: Strong convergence theorems for countable families of multivalued nonexpansive mappings and systems of equilibrium and variational inequality problems. Ann. Univ. Ferrara (2012). doi:10.1007/s11565-012-0156-6

28. Shehu, Y: Iterative methods for family of strictly pseudocontractive mappings and system of generalized mixed equilibrium problems and variational inequality problems. Fixed Point Theory Appl. 2011, Article ID 852789 (2011). doi:10.1155/2011/852789

29. Wang, ZM, Kang, MK, Cho, YJ: Convergence theorems based on the shrinking projection method for hemi-relatively nonexpansive mappings, variational inequalities and equilibrium problems. Banach J. Math. Anal. 6(1), 11-34 (2012)

30. Wangkeeree, $R$, Wangkeeree, $R$ : Strong convergence of the iterative scheme based on the extragradient method for mixed equilibrium problems and fixed point problems of an infinite family of nonexpansive mappings. Nonlinear Anal. Hybrid Syst. 3, 719-733 (2009)

31. Rodjanadid, B: Iterative algorithms for finding common solutions of generalized mixed equilibrium problems and common fixed point problems for a countable family of nonexpansive mappings in Hilbert spaces. Int. J. Math. Anal. 5(39), 1943-1960 (2011)

32. Klin-eam, C, Suantai, S: Strong convergence of composite iterative schemes for a countable family of nonexpansive mappings in Banach spaces. Nonlinear Anal. 73, 431-439 (2010)

33. Peng, JW, Yao, JC: A new hybrid-extragradient method for generalized mixed equilibrium problems and variational inequality problems. Taiwan. J. Math. 12(6), 1401-1432 (2008)

34. Zeng, WY, Huang, NJ, Zhao, CW: Viscosity approximation methods for generalized mixed equilibrium problems and fixed points of a sequence of nonexpansive mappings. Fixed Point Theory Appl. 2008, Article ID 714939 (2008). doi:10.1155/2008/714939

35. Peng, JW, Liou, YC, Yao, JC: An iterative algorithm combining viscosity method with parallel method for a generalized equilibrium problem and strict pseudocontractions. Fixed Point Theory Appl. 2009, Article ID 794178 (2009). doi:10.1155/2009/794178

36. Wangkeeree, R, Kamraksa, U: An iterative approximation method for solving a general system of variational inequality problems and mixed equilibrium problems. Nonlinear Anal. Hybrid Syst. 3(4), 615-630 (2009)

37. Jaiboon, C, Kumam, P: A general iterative method for addressing mixed equilibrium problems and optimization problems. Nonlinear Anal., Theory Methods Appl. 73(5), 1180-1202 (2010)

38. Chamnarnpan, T, Kumam, P: Iterative algorithms for solving the system of mixed equilibrium problems, fixed-point problems, and variational inclusions with application to minimization problem. J. Appl. Math. 2012, Article ID 538912 (2012). doi:10.1155/2012/538912

39. Cholamjiak, P, Suantai, S, Cho, YJ: Strong convergence to solutions of generalized mixed equilibrium problems with applications. J. Appl. Math. 2012, Article ID 308791 (2012). doi:10.1155/2012/308791

40. Nadler, SB Jr.: Multi-valued contraction mappings. Pac. J. Math. 30, 475-488 (1969)

41. Sastry, KPR, Babu, GVR: Convergence of Ishikawa iterates for a multivalued mapping with a fixed point. Czechoslov. Math. J. 55, 817-826 (2005)

42. Panyanak, B: Mann and Ishikawa iterative processes for multivalued mappings in Banach spaces. Comput. Math. Appl. $54,872-877(2007)$

43. Hussain, N, Khan, AR: Applications of the best approximation operator to *-nonexpansive maps in Hilbert spaces. Numer. Funct. Anal. Optim. 24, 327-338 (2003)

44. Hu, T, Huang, JC, Rhoades, BE: A general principle for Ishikawa iterations for multivalued mappings. Indian J. Pure Appl. Math. 28, 1091-1098 (1997) 
45. Cholamjiak, W, Suantai, S: Approximation of common fixed points of two quasi-nonexpansive multi-valued maps in Banach spaces. Comput. Math. Appl. 61, 941-949 (2011)

46. Cholamjiak, P, Cholamjiak, W, Cho, YJ, Suantai, S: Weak and strong convergence to common fixed points of a countable family of multi-valued mappings in Banach spaces. Thai J. Math. 9, 505-520 (2011)

47. Eslamian, M, Abkar, A: One-step iterative process for a finite family of multivalued mappings. Math. Comput. Model 54, 105-111 (2011)

48. Abbas, M, Khan, SH, Khan, AR, Agarwal, RP: Common fixed points of two multivalued nonexpansive mappings by one-step iterative scheme. Appl. Math. Lett. 24, 97-102 (2011)

49. Kim, TH, Xu, HK: Strongly convergence of modified Mann iterations for with asymptotically nonexpansive mappings and semigroups. Nonlinear Anal. 64, 1140-1152 (2006)

doi:10.1186/1687-1812-2013-236

Cite this article as: Bunyawat and Suantai: Hybrid methods for a mixed equilibrium problem and fixed points of a countable family of multivalued nonexpansive mappings. Fixed Point Theory and Applications 2013 2013:236.

Submit your manuscript to a SpringerOpen ${ }^{\odot}$ journal and benefit from:

- Convenient online submission

- Rigorous peer review

- Immediate publication on acceptance

- Open access: articles freely available online

- High visibility within the field

- Retaining the copyright to your article

Submit your next manuscript at $>$ springeropen.com 